\title{
Production losses attributable to suicide deaths in European Union
}

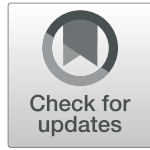

Błażej Łyszczarz@i]

\begin{abstract}
Background: Suicide is an important public health problem with multidimensional consequences for societies. One of the under-researched areas of suicide consequences are cross-country analyses of production losses associated with these deaths. The aim of this study was to estimate the production losses (indirect cost) of suicide deaths in 28 European Union states (EU-28) in 2015.

Methods: The study used societal perspective and human capital approach to investigate production losses due to suicide mortality at working age. Eurostat's data on the number of deaths was used to identify suicide mortality burden in terms of years of potential productive life lost. Labour and economic indicators were applied to proxy the discounted value of potential economic output lost. A one-way deterministic sensitivity analysis was conducted to test the robustness of the estimates.

Results: The production losses attributable to suicide deaths in EU-28 in 2015 were $€ 9.07$ billion. The per suicide indirect cost of these deaths was $€ 231,088$ for the whole EU-28 population; Luxembourg experienced the highest per suicide burden of $€ 649,148$. The per capita production losses of suicides in EU-28 was $€ 17.80$ and Ireland experienced the highest per capita burden of €48.57. The losses constituted an economic burden of $0.061 \%$ of EU28's GDP and this share ranged from $0.018 \%$ in Cyprus to $0.161 \%$ in Latvia. Most of the losses (71-91\%) were due to men's deaths. The results of the sensitivity analysis exhibit a large variation of losses; the highest (lowest) cost was identified with no adjustment for lower employment rates among those dying by suicide (adjustment for minimum productivity) and was $92.3 \%$ higher (59.7\% lower) on average than in the base scenario.
\end{abstract}

Conclusion: Public health actions aimed at prevention of suicides might reduce their health burden but also contribute to the economic welfare of European societies.

Keywords: Suicides, Production losses, Indirect costs, European Union

\section{Background}

Suicide, being in the top twenty causes of death worldwide, is considered to be a global health problem. Around 800 thousand people die from suicide each year [1] and over 56,000 of 5.2 million deaths in the European Union (EU) in 2015 were due to intentional self-harm [2]. The consequences of suicide are numerous; for a typical death by suicide, at least six people are directly affected in terms

Correspondence: blazej@cm.umk.pl

Department of Health Economics, Faculty of Health Sciences, Nicolaus Copernicus University in Toruń, ul. Sandomierska 16, 85-830 Bydgoszcz, Poland

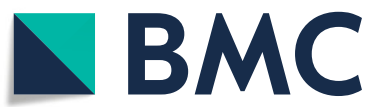

of human suffering [3]. Moreover, major economic consequences, including increased medical utilization, time absent from work, and production output lost are experienced by several groups $[3,4]$.

Previous contributions aiming at assessing the cost of suicides, include studies from the United States [5-8], Poland [9], Ireland [10], Australia [4, 11] and Spain [12] among others. However, this topic seems to be understudied; so far no systematic reviews have been published and the only cross-country study on the cost of suicide is concerned with the youth deaths in highly developed countries [13]. International comparisons of suicides' cost

(c) The Author(s). 2021 Open Access This article is licensed under a Creative Commons Attribution 4.0 International License, which permits use, sharing, adaptation, distribution and reproduction in any medium or format, as long as you give appropriate credit to the original author(s) and the source, provide a link to the Creative Commons licence, and indicate if changes were made. The images or other third party material in this article are included in the article's Creative Commons licence, unless indicated otherwise in a credit line to the material. If material is not included in the article's Creative Commons licence and your intended use is not permitted by statutory regulation or exceeds the permitted use, you will need to obtain permission directly from the copyright holder. To view a copy of this licence, visit http://creativecommons.org/licenses/by/4.0/ The Creative Commons Public Domain Dedication waiver (http://creativecommons.org/publicdomain/zero/1.0/) applies to the data made available in this article, unless otherwise stated in a credit line to the data. 
are difficult because particular studies use different methodological approaches, data sources and encompass various cost components. The most comprehensive approaches to the economic burden of suicide include estimation of following cost categories: medical care costs (direct costs), autopsy and investigation costs (medicolegal costs), production losses (indirect costs) and cost of pain and stress (intangible costs). Such studies provide an overall picture of suicides' cost but are only feasible in a national context and require exhaustive and reliable data sources. This research aims to overcome the low comparability of previous findings from different countries by estimating a single cost category of production losses associated with suicide mortality across the $28 \mathrm{EU}$ countries. With the use of uniform data from all the EU states, the study provides highly comparable estimates of the European states' economic burden of suicide. Although, suicide mortality is only a single cost category, several studies show that it is a crucial one which constitutes a majority of economic burden of suicide with shares of total economic cost as large as $91-98 \%$ in the United States [5-7], 94\% among Australian youth [4] and 84\% in New Zealand [14]. Moreover, this single cost category has also been subject to previous studies $[9,12]$ concerned with the production losses attributable to completed suicides solely.

Therefore, the aim of this study was to estimate the production losses (indirect cost) associated with suicide mortality among population at working age in the $28 \mathrm{EU}$ countries in the year 2015. Understanding the magnitude of this economic burden is important for assessing potential savings from cost-effective suicide prevention programmes. With introduction of such programmes, the number of suicide deaths could be reduced bringing benefits in terms of not only lives saved and trauma avoided but also economic output gained. Moreover, the estimates provided here might be useful to compare the economic burden of various health problems and, as such, to facilitate prioritization of health policy choices both nationally and at a supranational level.

\section{Methods}

The methodological approach used in this research builds on a model designed to estimate the production losses of premature mortality [15] which also has recently been applied for assessment of indirect cost associated with alcohol-attributable mortality [16] in EU countries.

\section{General modelling approach}

The study used population-based data, the societal perspective $[17,18]$ and human capital approach (HCA) $[19,20]$ to estimate the production losses attributable to premature mortality associated with suicides in the 28
EU countries. Premature mortality is defined as those cases of death that occur at working age. The study only accounts for losses borne in formal economy while it does not encompass the value of informal activities foregone due to suicide deaths. With the use of HCA, the indirect cost of mortality was proxied by the discounted value of economic output that would be produced if those who died prematurely were still alive and working until the average age of exiting labour market [21, 22]. Per worker gross domestic product (GDP) was used to measure productivity and the estimates were adjusted for the decreasing marginal productivity of labour by applying a 0.65 adjustment coefficient. Generally, the use of marginal productivity is a preferred choice over average productivity in indirect cost estimation [23, 24] and, therefore, this coefficient was used to account for the law of diminishing marginal productivity. This adjustment results from the fact that the production process relies on several inputs and diminishing one of them (labour) affects only a respective proportion of the production output $[25,26]$. Hence, the production lost due to suicide deaths should not be considered to be as high as the average output. The value of 0.65 used reflects the proportion of output attributable to labour by applying a relationship between marginal and average labour productivity; therefore, this adjustment reflects output elasticity of labour in Cobb-Douglas production function as used in the European context [27].

Unless stated otherwise, all the data refer to the year 2015.

\section{Data sources}

The age- and gender-specific data on the number of suicides was taken from Eurostat's dataset of death causes which reports figures on intentional self-harm mortality [28]. The country-specific data on labour market characteristics used to determine the duration of working life was taken from European Commission's report on aging [29] (the average effective age of exit from labour market), Eurostat's database [30] (the employment rates) and provided by Eurostat on the author's request (the average age of starting first regular job). The population and economic output data was taken from Eurostat [31], while the future country-specific potential per worker GDP growth rates from report [29]. The lower employment rates in the suicide population were proxied by the country-specific data on employment among those with chronic depression [32], which was the only available measure to proxy employment in suicide population for a range of EU countries.

\section{Estimation strategy}

In the first stage, the age- and sex-specific number of suicide deaths at 5 -years age intervals $(0-4 ; 5-9 ; \ldots ; 60-$ 
64; 65-69 years) was extracted from Eurostat database. In order to identify the production loss at a particular age, it was necessary to identify the number of deaths at this certain age. It could be done by assuming that the distribution of deaths in particular intervals was even. ${ }^{1}$ The average number of suicide deaths throughout the 3year period of 2014-2016 was used in order to remove the effect of unusual variation in mortality, particularly observable in low populated countries [15]. A half-cycle adjustment was applied meaning that all deaths occurred in the middle of the year [33]. The measure of years of potential productive life lost (YPPLL) $[9,34]$ was used to weight suicide cases occurring at various ages.

The second stage was to identify the mean time a person at each age would work if had not died from suicide; the following country- and sex-specific labour market measures were used for this purpose: the average age of starting first regular job ${ }^{2}$; the average age of exiting the labour market (data for the year 2016) [29]; and (5-years) age-specific employment rates ${ }^{3}$ [30]. These measures were assumed to be unchanged in future, because of the uncertainty of labour market situation in the years to come. Using these labour measures, the average time of work lost due to suicide death was identified separately for men and women at every working age for each of the states.

The average production lost due to suicide was proxied by per worker GDP adjusted for purchasing power parity (PPP $)^{4}$ and marginal productivity coefficient $(0.65)$. However, to reflect the fact that those dying from suicide are less likely to work, the employment rates of people reporting chronic depression [32] were used and these ranged from 29.5 to $73.0 \%$ of employment rates of those without depression in Cyprus and Germany, respectively. The reasoning for using this measure was based on the fact that at least $90 \%$ people who die from suicide have suffered from mental disorders with depression being a major one [35]; moreover, previous studies allocate $50-70 \%$ of suicides to those who have suffered

\footnotetext{
${ }^{1}$ For example, supposing that there were 85 suicide deaths among males aged 30-34, it was assumed that there were 17 deaths at each age in this interval.

${ }^{2}$ For Denmark and Sweden data was not available and sex-specific average values for the remaining EU countries were used.

${ }^{3}$ For $15-19$ years of age employment rates I used $20-24$ years employment rates because of low reliability and missing values in the former age interval for several countries (data for 4th quarter of 2015). This might bias the estimates upwards because employment rates are higher in the older age interval. Yet, this bias does not seem to have large impact on results as the number of suicides in the 15-19 age group is generally low. Moreover, in a majority of the countries the age of starting a first job is close to the upper bound of the age interval (19 years) and the employment rates at this age are plausibly closer to the rates for 20-24 years age interval.

${ }^{4}$ Purchasing power parity of a particular country indicates how many units of national currency is needed in that country in order to maintain the purchasing power of one euro in the EU.
}

from depression [36-38]. However, this choice seems to be conservative comparing to the previous studies which assume much lower employment differences between general and suicide populations, e.g. a 2.25\% employment rate gap in the Irish [10] and Scottish [39] studies.

The future losses were discounted using a 5\% rate and country-specific potential per worker GDP growth rates for each forthcoming decade [29] were applied to reflect the growth of the EU economies.

The formulas used for calculating the production losses are depicted in Fig. 1.

\section{Sensitivity analysis}

A one-way deterministic sensitivity analysis ${ }^{5}$ was performed to test the magnitude of changes in the model's parameters. The following sensitivity scenarios were used: a 3.5 and $0 \%$ discount rate (DR); a \pm 0.05 variation of the 0.65 correction coefficient; gross value added ${ }^{6}$ (GVA) instead of GDP and 0 and $2 \%$ future economic growth for all the countries. To deal with uncertainty in the future labour market situation two scenarios using homogeneous data for all the states were assumed: average EU values of labour measures; and ages 18 and 67 used as the ages of labour market entry and exit, respectively [15]. Also, scenarios were tested in which all deaths occurred among minimally productive workers ${ }^{7}$; and with no depression-specific labour employment rate adjustment. Eventually, all the deaths (for those aged 10+ years of age) reported as events of undetermined intent were added to suicide cases to make an attempt to account for under-reporting of suicides. The other possible scenario to be included into sensitivity analysis would be to differentiate male and female productivity. Unfortunately, no sex-specific data on average GDP produced is available and the only figure broken down by sex which could be potentially useful was gender pay gap. This last measure is considered to reflect rather labour market discrimination $[40,41]$ than real productivity differences; thus, it was not included as a sensitivity scenario.

\footnotetext{
${ }^{5} \mathrm{~A}$ 'one-way' sensitivity analysis refers to a single change of input parameter (e.g. discount rate) at a time with other parameters held constant. 'Deterministic' character of sensitivity analysis means that the isolated effects of changes in individual parameter is assessed, while 'probabilistic' sensitivity analysis assumes joint parameter uncertainty.

${ }^{6}$ Gross value added is an alternative (to GDP) measure of productivity; the relationship between GDP and GVA is: GVA = GDP - Taxes on products + Subsidies on products. GVA is sometimes considered to be a superior to GDP in assessing economic welfare of population.

${ }^{7}$ The minimal productivity was obtained by dividing minimum wage by average wage in particular economies; for details see the note of Table 3.
} 


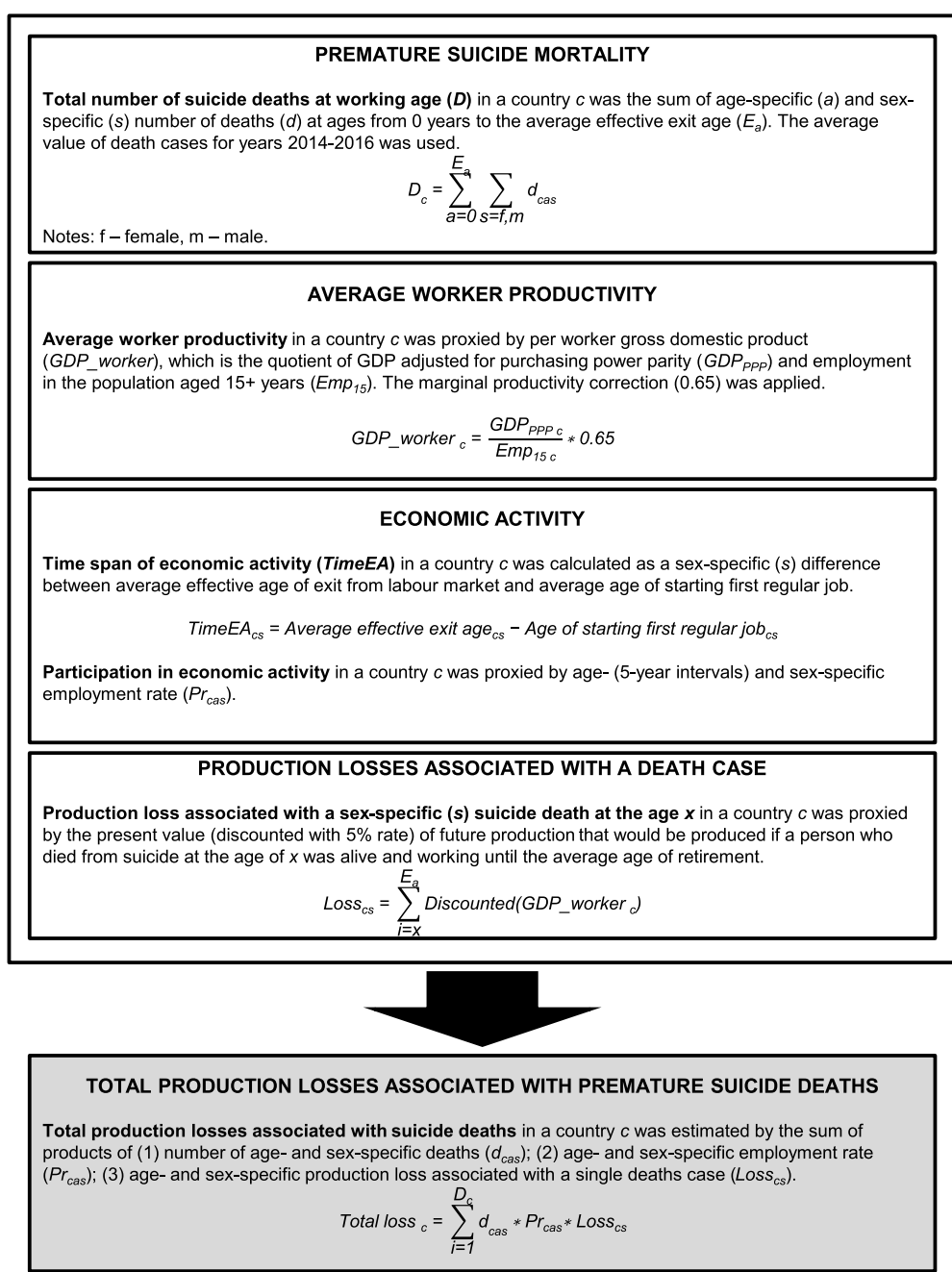

Fig. 1 Formulas for calculating production losses associated with suicide deaths in European Union

\section{Results}

\section{Suicide mortality at working age and YPPLL}

There were 39,265 (estimated) deaths at working age due to suicide in the European Union in 2015 (Table 1). The number of deaths was highest in the Western Europe (WE) countries (16,085 cases) followed by the Central and Eastern Europe (CEE) (9010), Northern Europe (NE) (7315) and Southern Europe (SE) (6854) countries. A majority of the premature deaths was associated with men's suicides (from $75.3 \%$ in WE countries to $86.2 \%$ in CEE countries). The suicide rate for the whole EU community was 7.7 cases per 100,000 population and 3.2 (12.4) for women (men). The overall suicide rate was highest in the CEE states (9.9 cases per 100,000 population) and lowest in SE (5.0). Men's suicide rate was disproportionally high in CEE (17.6) where it was more than twice of the rate in SE (7.9). On the other hand, the rate for women was more even in the subregions with the highest values in WE (4.2) and NE
(3.3). The countries with the greatest number of suicides at working age were Germany (6438), France (5863) and Poland (4433) while there were less than 40 cases of such deaths in Cyprus, Luxembourg and Malta. However, the relative burden of suicide deaths was highest in Lithuania (23.4 cases per 100,000 pop.), Latvia (13.9) and Belgium (12.4) while the rate of suicides was lowest in Greece (3.3 cases), Cyprus (4.1) and Italy (4.3).

Suicide mortality led to 745,020 YPPLL in the EU and this number was highest in the WE states $(288,792)$ followed by the CEE $(171,208), \operatorname{NE}(159,963)$ and SE countries $(125,057)$. The number of YPPLL was three to seven times higher for men's suicides compared to women's and the difference between the sexes in this respect was most pronounced in CEE. The YPPLL rate was 14.6 per 10,000 population in the whole EU (5.8 for women and 23.8 for men) and ranged from 9.2 in SE to 18.9 in CEE. The rates of YPPLL associated with men's suicides were much higher than those of women's in all 


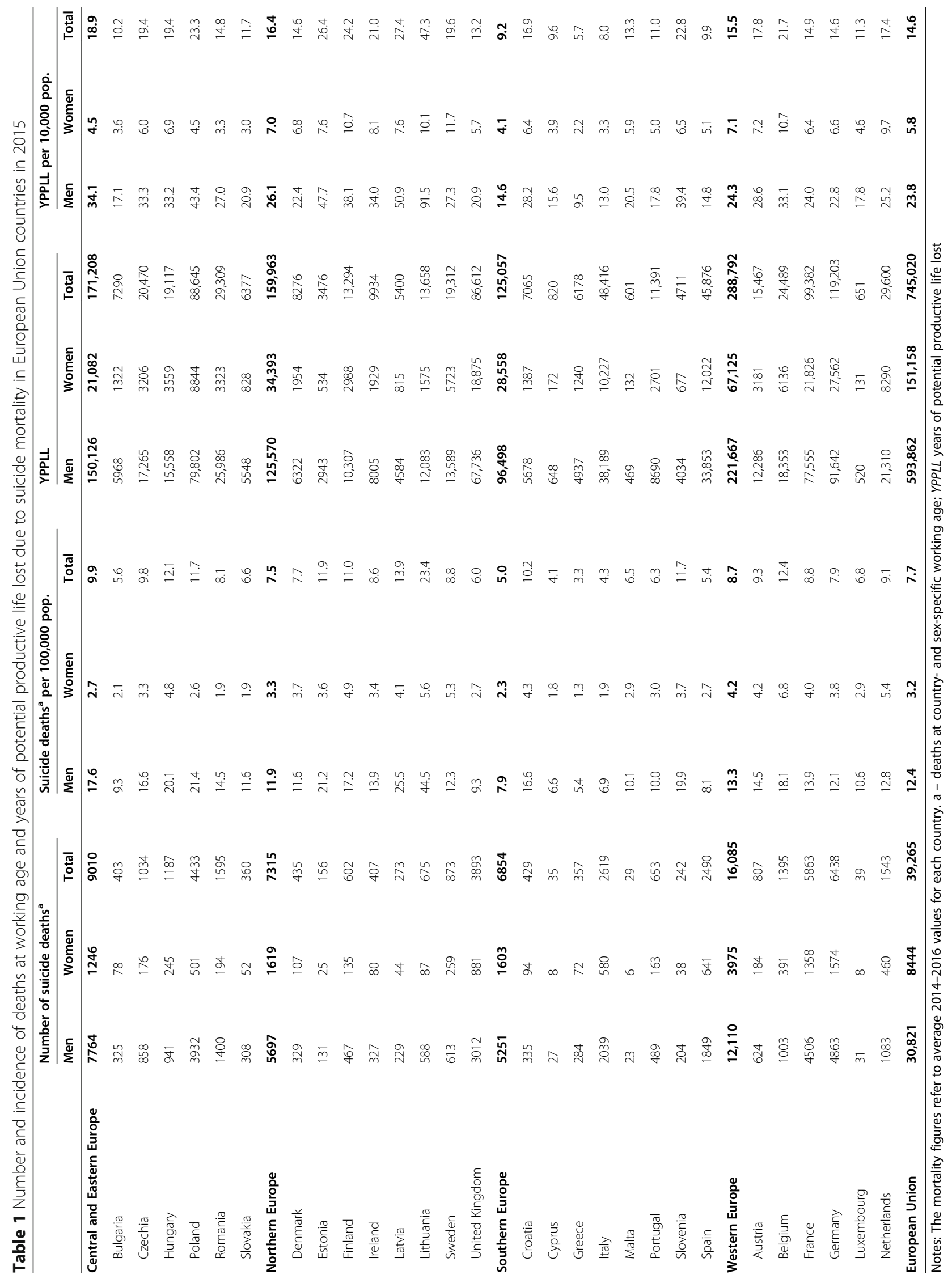


the sub-regions. The YPPLL rate (per 10,000 pop.) was highest in three Baltic states - Lithuania (47.3), Latvia (27.4) and Estonia (26.4) - while it was lower than ten in four SE countries, namely Greece (5.7), Italy (8.0), Cyprus (9.6) and Spain (9.9).

\section{Production losses associated with suicide mortality}

The total production losses (indirect cost) associated with suicide mortality at working age in 2015 were $€ 9.07$ billion in the EU and almost half of this burden was observed in the WE countries ( $€ 4.50$ billion). The cost in other sub-regions was $€ 1.16$ billion in $\mathrm{SE}, € 1.43$ billion in CEE and $€ 1.98$ billion in NE (Table 2). A vast majority of this cost was due to male mortality (from $78.8 \%$ in WE to $89.0 \%$ in CEE). The indirect cost was highest in Germany ( $€ 2.04$ billion), France ( $€ 1.60$ billion) and the United Kingdom ( $€ 1.00$ billion) while it was less than $€ 10$ million in Cyprus ( $€ 3.6$ million) and Malta ( $€ 5.5$ million). In relative terms, the economic burden of suicide mortality in the whole EU economy was $0.061 \%$ of GDP and ranged from $0.033 \%$ in SE countries to $0.081 \%$ in CEE. The highest share of GDP lost was estimated for three Baltic states - Latvia (0.161\%), Lithuania (0.143\%) and Estonia $(0.124 \%)$ - while this burden was lowest in Cyprus (0.018\%), Greece (0.022\%) and Italy $(0.030 \%)$.

The indirect cost of suicide mortality per capita in 2015 was $€ 17.80$ in the EU ( $€ 14.41$ for male and $€ 3.39$ for female suicides). This average cost was highest in WE (€24.19) and NE (€20.36), followed by the CEE $(€ 15.77)$ and $\mathrm{SE}(€ 8.56)$ states. Ireland experienced the greatest per capita economic burden in absolute values with the indirect cost of $€ 48.57$ per person and other countries with large average losses were Luxembourg $(€ 44.07)$ and Finland $(€ 30.88)$. Finally, the average cost per suicide was $€ 231,088$ in the EU and varied subregionally from $€ 158,766$ in CEE to $€ 279,677$ in WE. This per suicide cost was highest in Luxembourg ( $€ 649$, 148), Ireland $(€ 564,178)$ and Sweden $(€ 327,070)$ while the lowest values were observed in Croatia $(€ 79,248)$, Bulgaria $(€ 91,160)$ and Romania $(€ 98,952)$. For the whole EU community, the indirect cost of a single male suicide was $16.5 \%$ higher than a female suicide.

In the whole group of countries, the highest share of mortality cost was associated with suicides of those at ages 30-39 and 40-49 years (Fig. 2; country-specific results in Additional file 1). A slightly lower share of total losses was due to young adults' suicides (20-29 years) and this share was higher for men than women. On the other hand, the relative magnitude of losses attributable to mortality among those being between 0 and 19 years of age was higher for women. Additionaly, the between-country variation in all these shares was much higher for women than men.

\section{Sensitivity analysis}

The one-way deterministic sensitivity analysis shows that the cost estimates are subject to notable variation as a result of changes in some of the model's parameters (Table 3). The high changes in the cost result from the scenario which does not account for decreased employment rate in suicide population; the production losses would be $92.3 \%$ higher on average if general population employment rates were applied (from $36.9 \%$ in Germany to $238.9 \%$ in Cyprus). On the other hand, the cost would be $59.7 \%$ lower on average if minimum productivity adjustment was used. Using the $3.5 \%$ discount rate raised the cost by $17.4 \%$ on average, with relatively low variation among countries (14.9-20.5\%). With no discounting, the indirect cost would be $86.5 \%$ higher on average. Using GVA instead of GDP as a productivity measure decreased the estimates by $11.6 \%$ on average. The assumption of $0 \%(2 \%)$ future economic growth changed the results by $-13.4 \%(3.8 \%)$ on average. The use of alternative data on labour market characteristics had minor effect on the losses estimated; with the entry age of 18 and exit age of 67 for both sexes the results changed by $5.5 \%$ on average with the highest (lowest) change of $14.9 \%$ (1.8\%) in Luxembourg (Sweden). When the average EU values for these labour measures were used for all the countries, the cost variation was even lower. Classification of all undetermined deaths as suicides had varying effect on estimates and this depended on the country; for Slovakia, the cost was as much as $77.4 \%$ elevated while for Italy it was only $0.1 \%$ higher. A detailed, country-specific sensitivity analysis is available online in Additional file 2.

\section{Discussion}

This is the first study which aims to identify the crosscountry economic burden of suicide in general population by estimating the production losses associated with suicide deaths in $28 \mathrm{EU}$ countries. By applying a HCA model and Eurostat data, I obtained highly comparable estimates which reflect the specificity of economic burden experienced in particular countries.

The total production losses attributable to suicides at working age in the EU in 2015 were $€ 9.07$ billion, being a result of 39,265 suicides and 745 thousand years of potential productive life lost. A notable geographical difference was observed among the member states both in terms of the suicide rates and cost itself. All in all, the countries experiencing the highest relative burden of suicides were three Baltic states (Estonia, Lithuania, Latvia), Poland and Finland. On the other hand, the ones with the lowest detrimental economic effect of suicides were Cyprus, Greece, Italy, Spain and Bulgaria. Therefore, the countries located in the southern regions of Europe experienced minor health and economic burden of suicide 


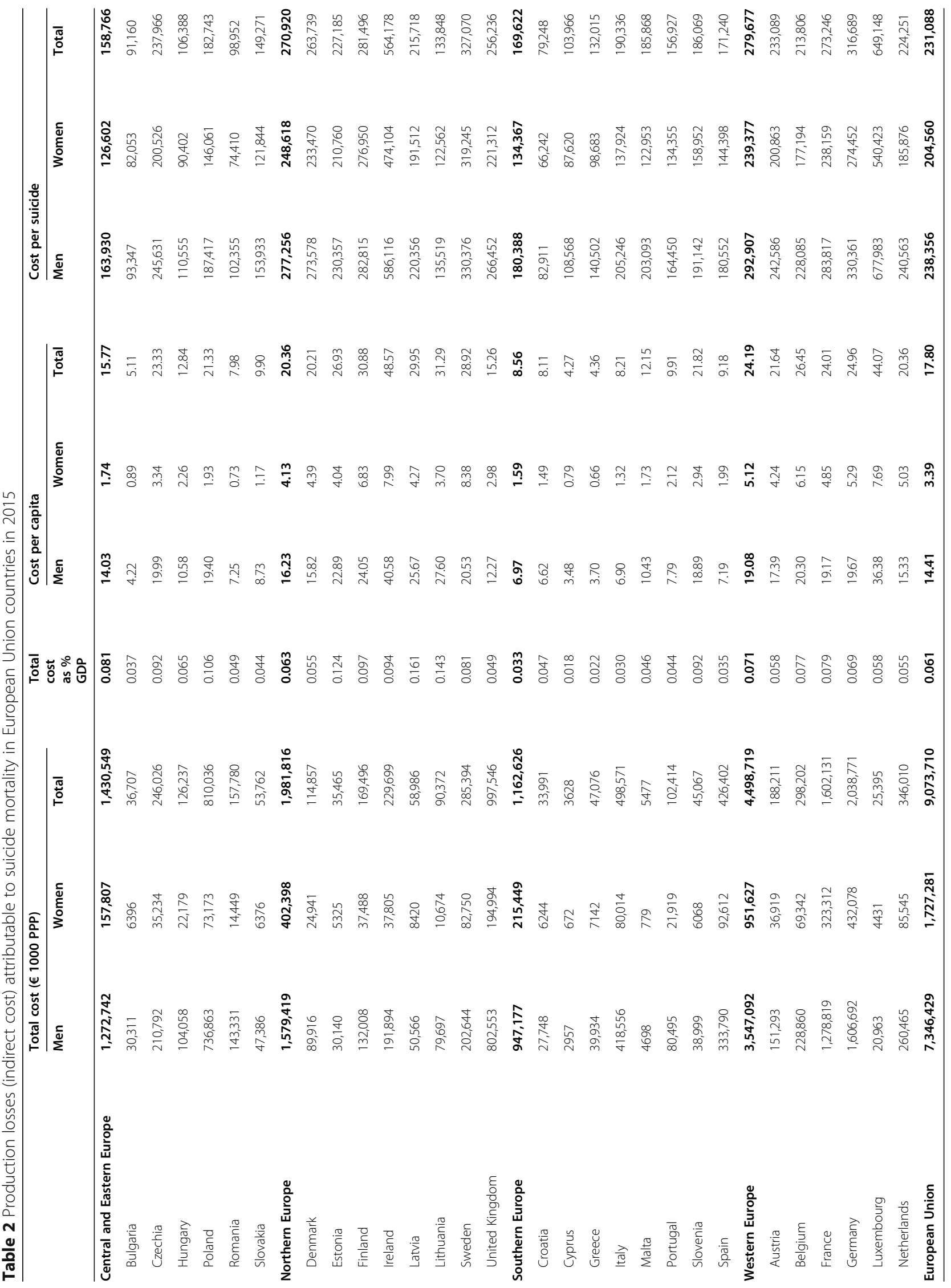



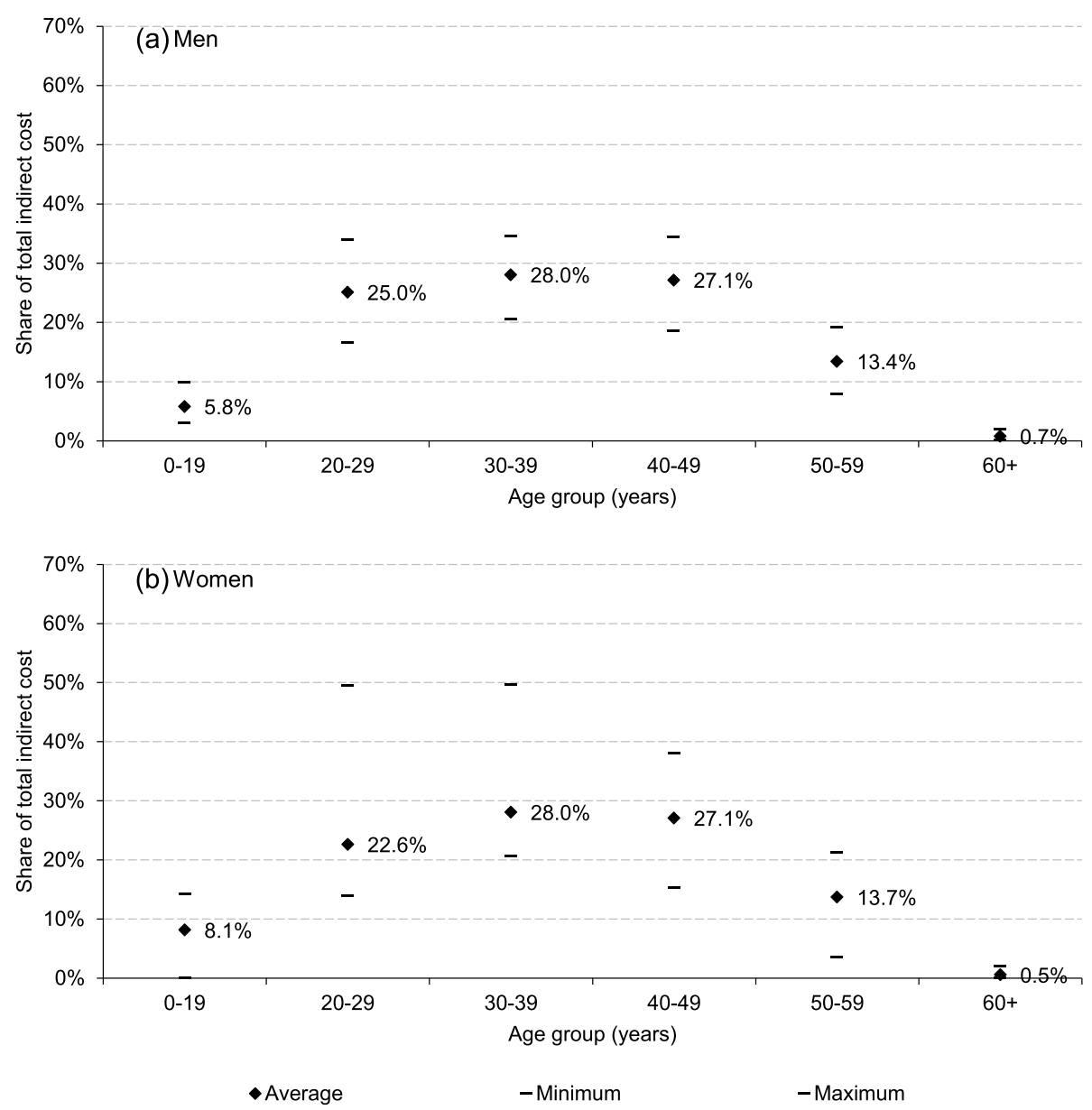

Fig. 2 Age groups distribution of production losses attributable to suicide mortality in European Union countries in 2015. Notes: Average shares are calculated as unweighted means

compared to those situated in the north. This clearly reflects the geographical distribution of suicide mortality, particularly low death rates in the Mediterranean states and higher rates in Scandinavia and the Baltic postSoviet republics. However, this mortality pattern is strengthened in terms of production losses because the NE states generally have higher employment rates (Denmark, Sweden, Latvia) and/or longer time of economic activity (Estonia, Ireland, Sweden) and/or higher prospects of future economic growth (Lithuania, Latvia, Estonia) than the SE countries. On the other hand, the greatest relative economic burden, measured by the share of GDP lost, in the CEE countries arises mainly from high suicide rates among men and dynamic projected economic growth which make future losses greater.

The results show that the cost of suicide is mainly driven by males' death and this obviously reflects the sex disparities in suicide incidence [42, 43]. As much as $89.0 \%$ of production losses were due to suicides of men in CEE and this share was $71.0 \%$ in Sweden, a country with the most even gender distribution of cost. Considering the age distribution of suicide cost, the highest burden was identified for those at the ages 30-39 and $40-49$ years. The age distribution of losses was similar for both sexes with a slightly higher magnitude of cost shares among women aged 0-19 years and young men (20-29 years).

The stability of results was tested using a one-way deterministic sensitivity analysis. The results changed notably with no discounting applied and this can be explained by the fact that suicide mortality is disproportionally high among relatively young people. Another scenario which varied estimates markedly was the use of general population employment rates instead of rates for depression population. It should be emphasized that this choice regarding employment rate is crucial for the indirect cost estimates. Yet, I decided to opt for the conservative scenario of a heavily reduced employment rate because the previous adjustment in this respect might be understated. For most other parameter changes used in the sensitivity analysis, the results' variation was lower. 
Table 3 Summary of sensitivity analysis for estimates of production losses attributable to suicide deaths in European Union countries in 2015

\begin{tabular}{|c|c|c|c|}
\hline & Average $^{a}$ change & $\begin{array}{l}\text { Minimum change from } \\
\text { base scenario }\end{array}$ & $\begin{array}{l}\text { Maximum change } \\
\text { from base scenario }\end{array}$ \\
\hline \multicolumn{4}{|l|}{ Discount rate (BS: 5\%) } \\
\hline $3.5 \%$ & $17.4 \%$ & $14.9 \%$ (Greece) & 20.5\% (Latvia) \\
\hline $0 \%$ & $86.5 \%$ & $71.1 \%$ (Greece) & $105.7 \%$ (Estonia) \\
\hline \multicolumn{4}{|c|}{ Coefficient to adjust for decreasing marginal labour productivity (BS: 0.65) } \\
\hline 0.6 & $-7.7 \%$ & $-7.7 \%$ (all countries) & \\
\hline 0.7 & $7.7 \%$ & $7.7 \%$ (all countries) & \\
\hline \multicolumn{4}{|c|}{ Productivity measure (BS: gross domestic product) } \\
\hline Gross value added & $-11.6 \%$ & $-7.4 \%$ (Ireland) & $-16.0 \%$ (Croatia) \\
\hline \multicolumn{4}{|c|}{ Minimum productivity adjustment ${ }^{\mathrm{b}}$ (BS: average productivity) } \\
\hline & $-59.7 \%$ & $-47.6 \%$ (Slovenia) & $-65.7 \%$ (Spain) \\
\hline \multicolumn{4}{|c|}{$\begin{array}{l}\text { No lower employment rate adjustment (BS: employment rate for those } \\
\text { reporting chronic depression) }\end{array}$} \\
\hline & $92.3 \%$ & 36.9\% (Germany) & 238.9\% (Cyprus) \\
\hline \multicolumn{4}{|l|}{ Future economic growth (BS: country-specific) } \\
\hline $0 \%$ for all the countries & $-13.4 \%$ & $-2.0 \%$ (Italy) & $-33.5 \%$ (Latvia) \\
\hline $2 \%$ for all the countries & $3.8 \%$ & $0.1 \%$ (Hungary) & $-19.9 \%$ (Latvia) \\
\hline \multicolumn{4}{|c|}{ Labour market entry and retirement age (BS: country-specific) } \\
\hline Sex-specific, average EU values & $-0.4 \%$ & $0.2 \%$ (Czechia) & 8.1\% (Luxembourg) \\
\hline Both sexes: 18 years and 67 years & $5.5 \%$ & $1.8 \%$ (Sweden) & 14.9\% (Luxembourg) \\
\hline Events of undetermined deaths included & $19.2 \%$ & $0.1 \%$ (Italy) & $77.4 \%$ (Slovakia) \\
\hline
\end{tabular}

Notes: $\mathrm{a}$ - unweighted average; $\mathrm{b}$ - minimal productivity was obtained by dividing the minimum wage by the average wage in particular economies. There was no minimum wage legislation in six EU countries in 2015 (Denmark, Italy, Cyprus, Austria, Finland, Sweden); therefore, the weighted (by population) average value for the remaining countries was used for the states with no minimum wage; this mean was 39.3\% of the average wage. Data for undetermined deaths in Cyprus was not available for none of the years; for some other countries and age intervals only some data was obtainable

Because this is the first cross-country study on the cost of suicide mortality in general population, the findings of this research could only be compared to previous estimates from single states. The recent results from Spain [12] identified the production losses of $€ 380.5$ million in 2013 (in 5\% DR scenario) which is a close value to my estimate of $€ 426.4$ million in 2015. This similarity is irrespective of some important differences in the methods and data sources used; e.g. for the productivity measure, the Spanish study applied gross salary while mine-GDP adjusted with 0.65 coefficient. The study from Poland [9] reported the indirect cost of completed suicides as equivalent to $€ 694.5$ million in 2012 (using 5\% DR) and this value is, again, comparable to my estimate of $€ 810.0$ million in 2015 for this country. This similarity might be surprising regarding the fact that my estimates are adjusted for lower employment rates among those who killed themselves. According to the conservative adjustment used here, the employment rates in the populations under study are 33.2 percentage points lower in Spain and 31.7 percentage points lower in Poland as compared to general employment rates. Therefore, this similarity of results seems to be coincidental. However, I argue that using employment rates for general population in a country bias the results upward because those dying by suicide are possibly less likely to work. Finally, the Irish study identified the cost of lost market output attributable to suicides in 2001 and 2002 to be $€ 205.9$ million and $€ 192.8$ million, respectively [10]. In my estimates, the value of market production lost in Ireland was $€ 229.7$ million in 2015 and the difference between the results of the two studies is low regarding a 13-14 years divergence of the time settings. The methodological discrepancies seem to explain this difference as the Irish estimates are based on employment rates revised downward by only 2.25 percentage points, while here this adjustment is of greater magnitude (27.1 percentage points). When it comes to estimates from nonEU developed countries, the most recent American study reported indirect cost of suicide deaths as being \$US 53.0 billion in 2013 [7], an equivalent of $0.32 \%$ of GDP. The share of GDP lost for this US study is more than double than the according share for Latvia-the country with the highest losses estimated here. However, the referred US estimates differ notably from mine in methodological terms, i.a. by including fringe benefits 
and household productivity losses while not accounting for lower productivity of those dying by suicide.

The major advantage of this research is the fact that it is the first study providing internationally comparable data on the production losses of suicide deaths, a major cost category of the total economic burden of suicides. Moreover, country-specific measures regarding labour market characteristics (real-life data on market entry and exit) and future economic growth are used and this reflects real differences among the countries investigated. With the use of homogenous data for these indicators, the peculiarities among the 28 states could not be unravelled.

On the other hand, the caveats of this analysis should also be pointed to. First, it only provides estimates on the burden of completed suicides in terms of potential production lost, while it does not investigate health care, medicolegal and intangible costs. However, the cost of mortality is a major cost driver of the suicideattributable economic burden; therefore, my estimates provide useful insight into the topic. Second, although the model uses homogenous data from a set of countries, some of the measures employed do not represent the reality in a perfect manner; e.g. the employment rates of those suffering from depression possibly deviate from the real employment among suicide population. Yet, it seemed to be the best choice available to account for different employment engagement of suicide population in particular countries. Moreover, such potential inaccuracies resulting from the use of proxy input data have been addressed by the sensitivity analysis. Third, the use of the HCA for the assessment of production losses is criticized for inflating the real economic burden $[22,23]$; still, it is the most common method for assessment of indirect cost and the alternative of the friction cost method has its own weaknesses [44]. The detailed discussion on pros and cons of the two methods is beyond the scope of this paper (and can be found elsewhere [24]) but the choice of HCA can be justified by the fact that also the previous studies used it and this allows for direct comparison between the cost estimates. Fourth, the estimates from this research might be biased downward because of under-reporting suicides [7, 45]; however, it is not clear how serious this issue is and under-reporting data is critically missing in international, comparable context [46]. Moreover, this is just one of the problems concerning validity and reliability of the suicide statistics. The cross-country study using WHO European mortality data shows that the quality of suicide statistics varies notably between countries while the reasons for this variability are numerous [47] making the magnitude of the figures' uncertainty difficult to assess. All and all, until now the ambiguous quality of suicides statistics appears to be an unsolved problem
[48] and the only reasonable way to account for this issue was to classify all the undetermined deaths as suicides in sensitivity analysis. However, the results appear not to be satisfactory in this scenario, because there is enormous by-country variation in this death cause category; e.g. there were only 2 deaths cases among men aged 10-69 years in Italy in 2015 while in Poland-which has lower population than Italy-the according figure was 1240 . Finally, the analysis only accounts for the cost borne in formal economies and does not include the burden experienced in terms of household activities undone or unregistered production lost because of suicides. Unfortunately, with the data presently at hand, this shortcoming could not have been addressed.

\section{Conclusion}

Because suicide is an avoidable mortality risk factor, public health actions aimed at prevention of suicides might not only reduce its health burden but also contribute to societies' welfare. Therefore, preventive actions towards reduction of suicide incidence should be judged not only in terms of their cost but also benefits for production losses' reduction resulting from lower mortality rates achieved.

\section{Abbreviations}

BS: Base scenario; CEE: Central and Eastern Europe; DR: Discount rate; EU: European Union; EU-28: 28 European Union states; GDP: Gross domestic product; GVA: Gross value added; HCA: Human capital approach;

NE: Northern Europe; SE: Southern Europe; WE: Western Europe; YPPLL: Years of potential productive life lost

\section{Supplementary Information}

The online version contains supplementary material available at https://doi. org/10.1186/s12889-021-11010-5.

Additional file 1. Country-specific age groups distribution of production losses attributable to suicide mortality in European Union countries.

Additional file 2. Detailed, country-specific sensitivity analysis for estimates of production losses attributable to suicide deaths in European Union countries.

Additional file 3. Dataset.

\section{Acknowledgements}

The author thanks Agnieszka Matysiak for her language assistance and two anonymous reviewers for their valuable comments on the earlier versions of the manuscript.

\section{Author's contributions}

B.t. is the only author of the manuscript; he designed and conducted the study and wrote the manuscript. The author(s) read and approved the final manuscript.

\section{Authors' information}

Błażej Łyszczarz holds PhD in Economics and is currently Assistant Professor in Department of Health Economics, Faculty of Health Sciences, Nicolaus Copernicus University in Toruń, Poland.

Funding

No funding was received for this research. 


\section{Availability of data and materials}

The dataset generated and analyzed during the current study is available in Additional file 3.

\section{Declarations}

\section{Ethics approval and consent to participate}

The study did not involve any human participants; it relied solely on publicly available data collected for other purposes. Because this study was not an experiment I did not seek the ethics approval.

\section{Consent for publication}

Not applicable.

\section{Competing interests}

The author declares no competing interests.

\section{Received: 6 January 2021 Accepted: 6 May 2021}

Published online: 19 May 2021

\section{References}

1. World Health Organization. Suicide in the world: Global Health Estimates. Geneva: World Health Organization; 2019. Available at: https://www.who.int/ publications/i/item/suicide-in-the-world.

2. Just over 56,000 persons in the EU committed suicide. Eurostat. 2018. Available at: https://ec.europa.eu/eurostat/web/products-eurostat-news/-/ DDN-20180716-1? inheritRedirect=true\&redirect=\%2Feurostat\%2F.

3. Comans T, Visser V, Schuffman P. Cost effectiveness of a community-based crisis intervention program for people bereaved by suicide. Crisis. 2013; 34(6):390-7. https://doi.org/10.1027/0227-5910/a000210.

4. Kinchin I, Doran CM. The cost of youth suicide in Australia. Int J Env Res Pub He. 2018;15(4):672. https://doi.org/10.3390/ijerph15040672.

5. Palmer CS, Revicki DA, Halpern MT, Hatziandreu EJ. The cost of suicide and suicide attempts in the United States. Clin Neuropharmacol. 1995;18(S3): S25-33. https://doi.org/10.1097/00002826-199518003-00004.

6. Corso PS, Mercy JA, Simon TR, Finkelstein EA, Miller TR. Medical costs and productivity losses due to interpersonal and self-directed violence in the United States. Am J Prev Med. 2007;32(6):474-82. https://doi.org/10.1016/j.a mepre.2007.02.010.

7. Shepard DS, Gurewich D, Lwin AK, Reed GA, Silverman MM. Suicide and suicidal attempts in the United States: costs and policy implications. Suicide Life-Threat. 2016;46(3):352-62. https://doi.org/10.1111/sltb.12225.

8. Florence C, Simon T, Haegerich T, Luo F, Zhou C. Estimated lifetime medical and work-loss costs of fatal injuries - United States, 2013. MMWR-Morbid Mortal W. 2015;64(38):1074-7. https://doi.org/10.15585/mmwr.mm6438a4.

9. Orlewska K, Orlewska E. Burden of suicide in Poland in 2012: how could it be measured and how big it is? Eur J Health Econ. 2018;19(3):409-17. https://doi.org/10.1007/s10198-017-0892-8

10. Kennelly B. The economic cost of suicide in Ireland. Crisis. 2007;28(2):89-94. https://doi.org/10.1027/0227-5910.28.2.89.

11. Kinchin I, Doran CM. The economic cost of suicide and non-fatal suicide behavior in the Australian workforce and the potential impact of a workplace suicide prevention strategy. Int J Env Res Pub He. 2017;14(4):347. https://doi.org/10.3390/ijerph14040347.

12. Rivera B, Casal B, Currais L. Crisis, suicide and labour productivity losses in Spain. Eur J Health Econ. 2017;18(1):83-96. https://doi.org/10.1007/s10198-01 5-0760-3.

13. Doran CM, Kinchin I. Economic and epidemiological impact of youth suicide in countries with the highest human development index. PLoS One. 2020;15(5):e0232940. https://doi.org/10.1371/journal.pone.0232940.

14. O'Dea D, Tucker S. The cost of suicide to society. Ministry of Health: Wellington; 2005.

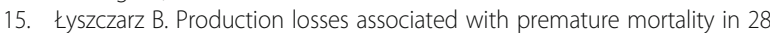
European Union countries. J Glob Health. 2019;9(2):020418. https://doi.org/1 0.7189/jogh.09.020418

16. Łyszczarz B. Production losses associated with alcohol-attributable mortality in the European Union. Int J Env Res Pub He. 2019;16(19):3536. https://doi. org/10.3390/ijerph16193536.

17. Neumann PJ. Costing and perspective in published cost-effectiveness analysis. Med Care. 2009;47(7_Supplement_1):S28-32. https://doi.org/10.1 097/MLR.0b013e31819bc09d.
18. Jönsson B. Ten arguments for a societal perspective in the economic evaluation of medical innovations. Eur J Health Econ. 2009;10(4):357-9. https://doi.org/10.1007/s10198-009-0173-2.

19. Akobundu E, Ju J, Blatt L, Mullins CD. Cost-of-illness studies: a review of current methods. Pharmacoeconomics. 2006;24(9):869-90. https://doi.org/1 0.2165/00019053-200624090-00005.

20. Jo C. Cost-of-illness studies: concepts, scopes, and methods. Clin Mol Hepatol. 2014;20(4):327-37. https://doi.org/10.3350/cmh.2014.20.4.327.

21. Zhang W, Bansback N, Anis AH. Measuring and valuing productivity loss due to poor health: a critical review. Soc Sci Med. 2011;72(2):185-92. https:// doi.org/10.1016/j.socscimed.2010.10.026.

22. Tarricone R. Cost-of-illness analysis: what room in health economics? Health Policy. 2006;77(1):51-63. https://doi.org/10.1016/j.healthpol.2005.07.016.

23. Koopmanschap MA, van Ineveld BM. Towards a new approach for estimating indirect costs of disease. Soc Sci Med. 1992:34(9):1005-10. https://doi.org/10.1016/0277-9536(92)90131-9.

24. Pike J, Grosse SD. Friction cost estimates of productivity costs in cost-ofillness studies in comparison with human capital estimates: a review. Appl Health Econ Health Policy. 2018;16(6):765-78. https://doi.org/10.1007/s402 58-018-0416-4.

25. Dubas-Jakóbczyk K, Kocot E, Seweryn M, Koperny M. Production lost due to cervical cancer in Poland in 2012. Med Pr. 2016;67(3):289-99. https://doi. org/10.13075/mp.5893.00378

26. Torój A, Mela A. Indirect costs of diabetes and its impact on the public finance: the case of Poland. Expert Rev Pharm Out. 2018;18:93-105.

27. Havik K, Mc Morrow K, Orlandi F, Planas C, Raciborski R, Röger W, et al. The production function methodology for calculating potential growth rates \& output gaps. Economic papers 535. European Commission: Brussels; 2014.

28. Eurostat. Causes of death - deaths by country of residence and occurrence. Available at: https://appsso.eurostat.ec.europa.eu/nui/show.do?dataset=hlth cd_aro\&lang=en.

29. European Commission. The 2018 ageing report: underlying assumptions and projection methodologies, institutional paper 065, Brussels 2017.

30. Eurostat. Employment rates by sex, age and citizenship (\%). Available at: https:/a ppsso.eurostat.ec.europa.eu/nui/show.do?dataset=Ifsq_ergan\&lang=en.

31. Eurostat. Database. Available at: https://ec.europa.eu/eurostat/data/database

32. OECD/EU. Health at a glance: Europe 2018: State of health in the EU cycle. Paris: OECD Publishing; 2018

33. Díaz-Jiménez D, Castañeda-Orjuela C, Castillo-Rodríguez L, De la HozRestrepo F. Economic costs analysis of the avoidable mortality in Colombia 1998-2011. Value Health Reg Issues. 2015;8:129-35. https://doi.org/10.1016/j. vhri.2015.08.007.

34. Yang B, Lester D. Recalculating the economic cost of suicide. Death Stud. 2007;31(4):351-61. https://doi.org/10.1080/07481180601187209.

35. Brådvik L. Suicide risk and mental disorders. Int J Env Res Pub He. 2018; 15(9):2028. https://doi.org/10.3390/ijerph15092028.

36. Sobocki $P$, Lekander I, Borgström F, Ström O, Runeson B. The economic burden of depression in Sweden from 1997 to 2005. Eur Psychiat. 2007; 22(3):146-52. https://doi.org/10.1016/j.eurpsy.2006.10.006.

37. Chang SM, Hong J-P, Cho MJ. Economic burden of depression in South Korea. Soc Psych Psych Epid. 2012;47(5):683-9. https://doi.org/10.1007/s0012 7-011-0382-8

38. Luppa M, Heinrich S, Angermeyer MC, König HH, Riedel-Heller SG. Cost-ofillness studies of depression: a systematic review. J Affect Disorders. 2007; 98(1-2):29-43. https://doi.org/10.1016/j.jad.2006.07.017.

39. Platt S, McLean J, McCollam A, Blamey A, Mackenzie M, McDaid D, et al. Evaluation of the first phase of choose life: the national strategy and action plan to prevent suicides in Scotland. Scottish Executive: Edinburgh; 2006.

40. Petersen T, Snartland V, Meyersson Milgrom EM. Are female workers less productive than male workers? Res Soc Strat Mobil. 2007:25:13-37.

41. Sin I, Stillman S, Fabling R. What drives the gender wage gap? Examining the roles of sorting, productivity differences, and discrimination. IZA discussion paper series, no. 10975. IZA - Institute of Labor Economics: Bonn; 2017.

42. Möller-Leimkühler AM. The gender gap in suicide and premature death or: why are men so vulnerable? Eur Arch Psy Clin N. 2003;253:1-8.

43. Payne S, Swami V, Stanistreet DL. The social construction of gender and its influence on suicide: a review of the literature. J Mens Health. 2008;5(1):2335. https://doi.org/10.1016/j.jomh.2007.11.002.

44. Krol M, Brouwer W, Rutten F. Productivity costs in economic evaluations: past, present, future. Pharmacoeconomics. 2013;31(7):537-49. https://doi. org/10.1007/s40273-013-0056-3. 
45. Pritchard C, Hansen L. Examining undetermined and accidental deaths as source of 'under-reported-suicide' by age and sex in twenty Western countries. Community Ment Health J. 2015;51(3):365-76. https://doi.org/10.1 007/s10597-014-9810-z.

46. Tøllefsen IM, Hem E, Ekeberg $\varnothing$. The reliability of suicide statistics: a systematic review. BMC Psychiatry. 2012;12(1):9. https://doi.org/10.1186/14 71-244X-12-9.

47. Värnik P, Sisask M, Värnik A, Arensman E, Van Audenhove $C$, van der FeltzCornelis CM, et al. Validity of suicides statistics in Europe in relation to undetermined deaths: developing the 2-20 benchmark. Inj Prev. 2012;18(5): 321-5. https://doi.org/10.1136/injuryprev-2011-040070.

48. Gjertsen F, Bruzzone S, Griffiths CE. Burden of suicide presented as one of the leading causes of death: uncover facts or misrepresent statistics? J Glob Health. 2019;9:010401.

\section{Publisher's Note}

Springer Nature remains neutral with regard to jurisdictional claims in published maps and institutional affiliations.

Ready to submit your research? Choose BMC and benefit from:

- fast, convenient online submission

- thorough peer review by experienced researchers in your field

- rapid publication on acceptance

- support for research data, including large and complex data types

- gold Open Access which fosters wider collaboration and increased citations

- maximum visibility for your research: over $100 \mathrm{M}$ website views per year

At BMC, research is always in progress.

Learn more biomedcentral.com/submissions 